the skin supply the mucous membrane and the muscular apparatus of the penis, - and I have done so for the purpose of displaying its utility in practice. Not long after $I$ had visited this young patient, a gentleman called upon me. When he came into my room he said, "You have performed a miracle, Sir." " A miracle !" I said, " you really take me by surprise. What do you mean?" "Why, you have cured young B-; he is quite well, and at school. Dr. __ said he would surely die from fits resulting from some constitutional influences inherited from his father and mother." I assured him that what I had done was no marvel; that I simply acted upon common sense, experience, and physiological deduction. With that as. surance and explanation he seemed to be satisfied, and so was I.

Mr. President and gentlemen, [ have to thank you for your very kind indulgence and self-sacrifice in coming so frequently to hear, perhaps to you, the trite observations of a surgeon who has had, upon the whole, large opportunities for clinical observation and experience. And now I must conclude this my third and last course of these discursive lectures. They have been of necessity desultory, because their object has been to establish a principle; and how difficult of attainment this object is in matters medical we need not to be reminded. It is familiar to us all, that one of the greatest impediments to the adrancement of accurate medical knowledge has been, in all times and under all the changeful phases of our professional progress, the tendency to rush inconsiderately into what has at one time been denominated hypothesis, and at another time theory, withont any exact appreciation of the terms employed. I prefer, however, the use of the term "principle," as we con. ventionally employ it, because $I$ intend it to imply a fundamental truth, congruous with and stringing together the sub. jects treated of.

Rest is a reality : pain is a truth. To study the interpretation of the one and the due application of the other, is but to pursue the simplest and most obvious phenomena which nature presents to us, up to the wide and comprehensive laws on which they depend and by which they are regulated.

In no other science (or combination of science and art) is it, perhaps, so essential that any attempt to establish a legitimate conclusion should be based on the broadest possible foundations, as in ours: and hence, in order to establish clearly that " rest is an important therapeutic agent in the cure of accidents and surgical cases," and to illustrate the priuciples of its varied application, I have been compelled, first, to survey, as fully as my time admitted, the marvellous contrivances which nature has adopted for the surety of rest to the different organs of the body when in health, seemingly as if it were the one great object which she had in view in the peculiarities of their formation; secondly, to depict the natural promptings to the effectuation of it, instinctively singrested, on the occurrence of accident or disease; and thirdly, to shadow forth the appliances for its attainment, which an accurate anatomical and physio. logical acquaintance with the structure and endowments of every organ and limb will whisper to the mind earnestly intent upon the employment of rest for their relief when in a state of disease or derangement. So also, for the purpose of impressing upon you "that every pain has its distinct and pregnant signification," if we will be at the pains to interpret it, at any rate to the extent of our present knowledge, I have striven to unravel and render patent, by the agency of a more precise nervous anatomy, the meaning of many pains which have been so often termed "obscure" or anomalous; and I have ventured to suggest that there is no field open to the future inquirer from the cultivation of which he will reap a reward richer in benefit to his race and his profession, than from the persevering attempt to explain the purport and true significance of the manifold pains by which nature admonishes us of hidden and otherwise imperceptible evils. From the pain of the conjunctiva on the intrusion of a particle of dust, and the closure of the eyelid for the procuration of rest, up to the most formidable diseases with which we have to deal, pain, the monitor, and rest, the cure, are, I am convinced, starting-points for contemplation which should be ever present to the mind of the surgeon in reference to his treatment. I hope, Sir, that I have not dogmatised or spoken presumptuously; because I feel that I have, at most, advanced but one short step towards the object of every scientific surgeon : which object was doubtless present to the mind of Dr. Darwin when writing the preface to his Zoonomia, in which he says-." A theory founded on nature, that should bind together the scattered facts of medical knowledge and converge in to one point of view the laws of organic life, would thus on many accounts contribute to the interests of society. art of healing with real advantage to the public; it would enable every man of literary attainments to distinguish the genuine disciples of medicine from those of boastful effrontery or of wily address; and would teach mankind in some important situations the knowledge of themselves." I may also adopt his quotation from Cicero, changed iuto the past tense, because it expresses so exactly what $I$ feel :- " Hæc, ut potui, explicavi : nec tamen, ut Pythius Apollo, certa ut sint, et fixa quæ dixi ; sed, ut homunculus unus ex multis, probiliora, conjectura sequens."

\section{ON THE MEDICINAL USE OF ARSENICATED} MINERAL WATERS,

\section{WITH SPECIAL REFERENCE TO THAT OF WHITBECK.}

By GEO. ROBINSON, M.D., F.R.C.P.L., FORMERLY LBCTOBEE ON TH $M$ PRACTICY OF PHYSIC AT THB NHWCASTLB-ON-TIMB COLLEGB OF MBDICINB.

THe last number of the Edinburgh Philosophical Journal contains a paper by Dr. John Davy "On the question, Is Oxide of Arsenic, long used in a very small quantity, injurious to Man?" founded chiefly on the facts observed in reference to the arsenical water of Whitbeck, in Cumberland. Having had the pleasure of accompanying Dr. Davy in one of his visits to this stream, and being well acquainted with the district, $I$ am induced to submit to the profession another question which has often presented itself to my mind-namely, whether a natural combination of arsenic, such as that occurring at Whitbeck, will not in many cases be found a more efficacious therapeutic agent than any artificial solution of arsenical compounds?

While fully admitting that the whole subject of the physiological action and medicinal employment of this powerful sub. stance requires careful and extended investigation, there cannot, I think, be any doubt that in many chronic intractable diseases arseric is one of the most potent remedies at our command. All writers on diseases of the skin bear concurrent testimony to its value in the treatment of lepra, eczema, and other still more loathsome forms of cutaneous disease, and one in particular lauds its "almost omnipotent influence" over the non-syphilitic forms of the malady, ascribing its occasional failure to the exhibition of the remedy in too large doses, and at intervals too distant.

Mr. Erasmus Wilson, in treating of lepra, says that he places the greatest reliance on arsenical preparations; but, in ordering the artificial solutions of this metal, admits the necessity of explaining to the patient the symptoms which call for the suspension or omission of the medicine, and alludes to the precautions requisite to guard against irritation of the stomach by its ingestion. And in the most recent contribution on this subject, the lectures of $\mathrm{Dr}$. $\mathrm{M}^{\circ} \mathrm{C}$ all Anderson, the same homage is paid to the superior efficacy of arsenic in the treatment of eczema. As regards this class of couplaints, I believe that the expe. rience of most practitioners is to the same effect. But there is another very extensive group of disorders in which arsenic has been very little employed, although it combines in itself the two therapeutic actions most essential to the patient's recovery -namely, an alterative and a tonic effect. I allude to those numerous cases in which there is a tendency to cachexia or dyscrasis accompanying, and possibly dependent on, a congested, torpid state of the liver and portal venous system; and one of the most obstinate and distressing varieties of this disorder is that in which mental depression, ranging from slight by pochondriasis to confirmed melancholia, accompanies the bodily disease, many instances of which have fallen under my uwn notice. These patients are at present often sent to some of the sulphuretted mineral waters, and derive a certain amount of benefit from their use. But I believe tbat arsenical waters given under the same conditions would be infinitely more effectual, the eliminative and alterative effect exercised being much greater in the one case than in the other, to say nothing of the specific action of arsenic upon the nervous system.

In brief, then, I submit that in these and many other diseases where the administration of arsenic is indicated, that remedy may be most safely, effectually, and pleasantly given 
by the internal and external use of a naturally arsenicated water.

The greater safety would result from the excessive and constant dilution of the medicinal substance by pure water, thus preventing any irritating or injurious effect upon the system. This is distinctly proved by the fact of the daily and habitual imbibition of the Whitheck water by the inhabitants of that village, as detailed by Dr. Davy.

The greater efficacy of the natural over any artificial solution of arsenic must be influenced by two chief circumstances: 1st, the adjuvants constituted by the pure air, delightful scenery, proximity to the sea, and the complete change of mental and bodily associations, involved in a visit to a district like that of Whitbeck; and 2nd, the peculiar state of combination in which the chief remedial substance exists in this particular water. And on this point I may be allowed to quote, verbatim, the remarks of Dr. Davy and Mr. Church, premising that the fact of the arsenical impregnation of the Whitbeck water was determined some years baci by Mr. Zenner, analytical chemist, of Newcastle, and was then understoon to be the necessary effect of the existence in this mountain of large masses of arsenical pyrites (mispickel).

Dr. Davy thus describes the water of Whitbeck:- " It had the general character of the mountain streams of the Lake District, was perfectly clear and colourless. and tasteless. Of the several specimens obtained I found the specific gravity the same, and the same as that of distilled or rain water. When evaporated to dryness the residue was very small, a pint yield. ing about 25 of a grain; and, from the different specimens tried, not varying more than one-tenth of a grain. In each instance this residue was found to consist chiefly of common salt; it tasted of this salt, and in solution was copiously precipitated by nitrate of silver. Mixed with the common salt was a little magnesia and lime, both probably in combination with sulphuric acid, as sulphate of lime and of magnesia, the presence of the acid being denoted by nitrate of barytes; a trace, too, of oxide of arsenic was detected in each, and, it may be inferred, in combination with potash, a trace of which was also obtained. The arsenic was detected not only by the test of the ammoniaco-nitrate of silver, but also by reduction to its metallic state by sublimation after mixture with ferrocyanide of potassium. Of the several specimens of water tried, that procured in October, when the stream was about its ordinary size, afforded a somewhat stronger trace of the metal than either the earlier or the later: the one in August, 1861, taken when the stream was swollen after rain; the other in January, 1862, during a frost of several days' duration, when probably the water was frozen at its sources-the stream then being lower than common. In noticing, however, the later, I should except the last-that taken in August last, when the stream was of about its average volume, and the indications of arsenic nearly the same as those of October. In the instance that the trace was strongest, judging from comparative experiments with oxide of arsenic-experiments of reduction by sublimation,- the quantity of oxide contained in the pint was only about $\cdot 00 \mathrm{~s}$ grain, or "064 grain to the gallon."

Mr. Church says: "The reaction of the water as it issues from the earth was faintly but unmistakably alkaline; on testing the water after ebullition the effect was more decided. The water from many other sources in the neighbourhood of Whitbeck, where decomposing granite is of common occurrence, has an alkaline reaction. 'The water, on examination, gave distinct indications of the presence of arsenic. This element, which here probably exists as an alkaline arsenite, occurs, not as a mere trace, but in determinate quantity. I have satisfied myself that in some seasons of the year the quantity present approaches a good fraction of a grain of arsenic (metallic) in each gallon of water. The arsenical water is habitually used for every purpose by the inhabitants of the little village of Whitbeck."

From these analyses it will be seen that the arsenic exists in the very same form as that in Fowler's solution-namely, as arsenite of potass; and from the circumstance of common salt being also present, $I$ have no doubt that a minute quantity of iodine is likewise contained in it. I may add, in reference to this point. that the sea is only a mile distant from the base of Black Combe, the mountain from which this stream descends.

Another great medicinal advantage offered by this mineral water is that it may be employed in the form of baths. For proof that arsenic, especially when in solution, is capable of being absorbed through the unbroken skin, I may refer to the

* Chemical News, Aug. 25th 1860. well-known and justly celebrated works of Dr. Alfred l'aylor; and on the same authority, confirmed by other testimony, it may be stated that this substance does not accumulate in the system. Continued doses of the mineral water of Whitbeck may therefore be given without any fear of poisonous sy mptoms suddenly manifesting themselves. In fact, the chief beneficial effects of arsenic probably result from the greater activity induced by it in all the eliminating organs of the body, by which retained secretions and other noxions matters are discharged, and a more healthy action of the depurating tissues induced.

Of the general salubrity of the district now under consideration, and of its many agreeable features as a place of resort for invalids, I can speak in the highest terms, and from personal experience, having for the last seven years visited it annually as a pleasant and salutary change from Newcastle. It is easy of access from all parts of the kingdom. There are within a short distance, especially in Whitehaven, several medical practitioners of high character and great ability; and were a demand to arise for increased accommodation for strangers consequent on the use of the Whitbeck water as a remedral agent, there is every reason to think that the public-spirited nobleman who is the clief landed proprietor in that neighbuurhood, and to whom the country is indebted for that boautiful part of England having been rendered more accessible, would afford all reasonable facilities.

I shall be glad if these few remarks serve to draw attention to the medicinal value of this and similar mineral waters, and need scarcely say that it will afford me much pleasure to supply to members of the profession any additional information in my power. For further particulars respecting the Wbitbeck water, [ may also refer to Dr. ])avy's paper; and, in leaving this sub. ject for the present, I may perhaps be allowed to congratulate my fellow-practitioners on the continued prosence amongst us of this distinguished philosopher. The veterans of science are not numerous in this country; and assuredly there is not one whose life has been marked by more unceasing industry than that of Dr. John Davy. From the time of his discovery of phosgene gas, half a century siuce, up to his very recent publications on Military Medicire and Physiology, every year has witnessed some fruits of his patient devotion to the study of Nature and to the cause of humanity; and it shonld be cheering and instructive to all of us to recognise in his latest contribution to medical science the same untiring energy and love of truth for its own sake which have been conspicuous throughout Dr. Davy's long and honourable career, and which have added a more varied lustre to a name that posterity will not willingly let die.

Welbeek-street, July, 1863.

\section{REPORT OF THE}

\section{CASUALTIES AT THE WIMBLEDON CAMP.}

BY JOHN G. WESTMACOTT, M.D.,

SURGBON, NATIONAL RIVLB ASSOCIATION; SEN. ASSIST.-SURG. LOND, SCOT. KIFLE YOUUNTEELS.

IT may perhaps interest such of the readers of THE LANCET as form the medical staff of our Volunteer Army to learn what casualties occurred during the encampment at Wimbledon (of twelve days), consisting of regulars, staff officers, volunteers, commissariat, armourers, commissioners, labourers, shoeblacks, \&c., at one time numbering about a thousand. Although the fourth year of the meeting of the National Rifle Association, this is the first that any medical officer has been required to do day and night duty, - the camp having extended from year to year, till it has now become of some magnitude, and completely organized. The second year I performed the day duty solus. Last year I attended every morning until a surgeon for the day arrived-one from certain of the Volunteer corps who tendered their services. This year it was thought advisable to appoint one regularly to the Association, and I accepted the appointment. The continued fine state of the weather during the whole time will no doubt account for the comparatively healthy condition of the camp, and, barring the accidents that happened, the illnesses were not of any great moment. Thirty-four cases in all occurred which required treatment. The most serious were the accidents which happened the first two or three days - the worst, that of Michael Fagan (School of Musketry), who lost his right eye from a bullet splash off the 